\title{
Research on an Improved Metal Surface Defect Detection Sensor Based on a 3D RFID Tag Antenna
}

\author{
Qiang Li (D), Jianbin Chen (D), and Liang Zhao \\ School of Information Engineering, Southwest University of Science and Technology, Mianyang, Sichuan 621010, China \\ Correspondence should be addressed to Qiang Li; liqiangsir@swust.edu.cn
}

Received 9 March 2020; Revised 9 May 2020; Accepted 15 May 2020; Published 8 July 2020

Academic Editor: Bin Gao

Copyright ( 2020 Qiang Li et al. This is an open access article distributed under the Creative Commons Attribution License, which permits unrestricted use, distribution, and reproduction in any medium, provided the original work is properly cited.

\begin{abstract}
Structural health monitoring (SHM) technology is a monitoring process and early warning method for the health status or damage of special workpiece structures by deploying sensors. In recent years, there have been many studies on SHM, such as ultrasonic, pulsed eddy current, optical fiber, magnetic powder, and other nondestructive testing technologies. Due to their sensor deployment, testing environment, power supply, and transmission line wiring mechanism, they bring problems such as detection efficiency, long-term monitoring, and unreliable systems. The combination of wireless sensing technology and intelligent detection technology is used to solve the above problems. Therefore, this paper studies the tag antenna smart sensor, which is used to characterize the extension of metal defects in SHM. Then, it presents a wireless passive three-dimensional sensing antenna, and simulations verify the feasibility of the antenna. The simulation results show that the antenna can characterize the two extension directions of depth and width of the metal surface structure smooth defect. At the same time, the antenna can characterize the position of smooth defects on the surface of metal structures relative to the antenna and then realize the smooth defect positioning.
\end{abstract}

\section{Introduction}

It is necessary that civil infrastructure applications must possess the necessary reliability and safety [1]. The development of civil building structure indicates that metal will be increasingly invested in infrastructure such as large buildings, bridges, and landmark buildings. The important load-bearing parts in this kind of engineering structure show structural fatigue caused by periodic load pressure and structural corrosion caused by harsh environments, especially those in longterm service and exposed environments. Those will lead to serious accidents. Hence, SHM technology monitors the components' degree of structural damage regularly. The aim is to achieve an effective online assessment of structural healthy life. It has become an extremely important safety prediction measure for catastrophic failures caused by failure of important components. Among many structural defects, the initial defect expansion mode is mainly transverse expansion in all strain paths [2]. The most dangerous defect is the transverse defect of structure [3], which will cause the bearing capacity of the structural frame to decrease rapidly. As a result, the structural frame will be easily broken during usage. Thus, it is particularly important to detect the transverse defect of the component structure. Structural defect monitoring is used to intuitively characterize structural damage. This is used as an essential indicator for structural health and service life assessment.

SHM is achieved by nondestructive testing methods without damaging the components being inspected, in industry, such as common visual inspection [4], ultrasonic inspection [5], eddy current inspection [6], and fiber optic inspection [7]. Visual inspection is a method by which a person periodically detects the degree of structural damage using auxiliary equipment [8], which has high labor costs, low detection efficiency, and environmental constraints. On the other hand, due to the low resolution of the artificial naked eye for microscopic changes in defects, this is prone to misjudgment and omission. Compared with visual inspection, ultrasonic detection, eddy current detection, and fiber detection technology have higher sensitivity and resolution. The test results are more reliability. However, these three types of tests also require manual inspection. Besides, the three 


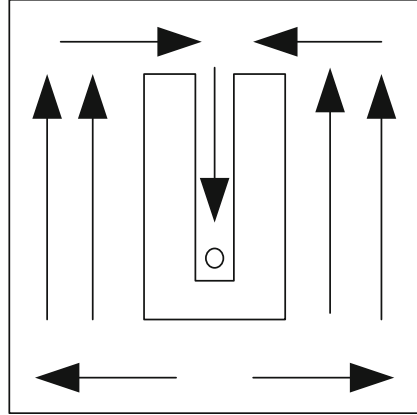

(a)

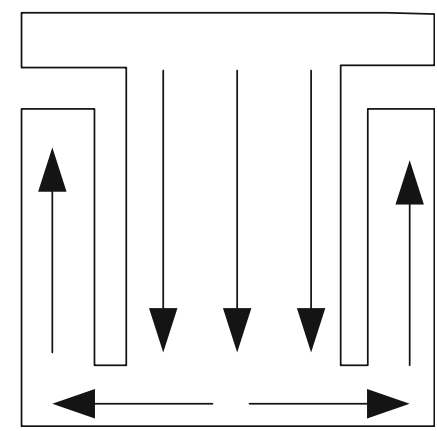

(b)

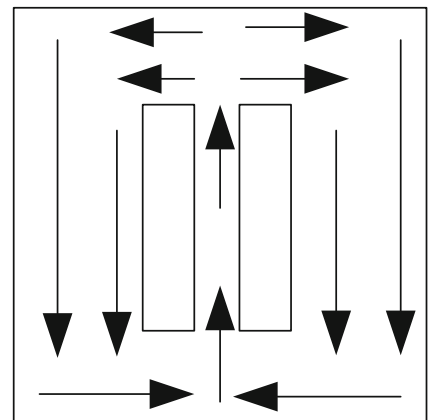

(c)

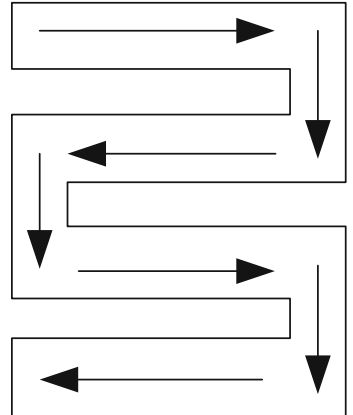

(d)

FIGURE 1: Schematic diagram of the meandering slot for the microstrip patch antenna. (a) U-slot current path. (b) L-slot current path. (c) Hslot current path. (d) Rectangular slotted current path.

methods are not only complicated in the detection process but also limited by large-scale structural inspection and large-area monitoring. In distributed detection systems, large-scale wiring is required to provide then power and signal transmission lines for sensors in the system. With the expansion of the detection range and increase in the number of sensor deployments, large-scale power lines and signal transmission lines need to be installed. If the system is worked for a long time, there will be many problems on the cables. Accordingly, more manpower and material resources will be invested in the inspection and maintenance system [9].

Wireless sensor networks can solve the wiring problems and reduce the cost investment of traditional embedded sensor detection systems [10]. Although there are many research studies on reducing wireless sensor networks' energy consumption [11], it is still unavoidable to use batteries with limited energy to power sensors. Furthermore, replacing a large number of batteries requires more workers and time. Investment of battery will also limit the sensor deployment granularity [12], and it will not meet the energy conservation and environmental protection measures [13]. Introducing the sensing capability into the radio frequency identification (RFID) system [14] and combining it with the Internet of Things technology [15], a wireless passive sensor detection system can be realized. So far, there have been many research studies on RFID sensor tag antennas, such as temperature detection [16], humidity detection [17], gas detection [18] in the environmental field, wireless displacement detection [19], and level detection in the field of industrial detection [20]. Based on the RFID sensor system, this paper studies and simulates a kind of tag antenna sensor, which can characterize extended information of metal defects.

\section{Literature Review}

Nondestructive testing based on RFID sensing technology, in the field of SHM, mainly focused on researching tag antennas for strain and defect sensing of test pieces. For strain antenna sensors, Kobayashi et al. manufactured an ultrathin piezoelectric strain sensor, which used a $5 \times 5$ array of monitors to make a reliable test for large equipment through different working voltages on the defective part, but this is an active
RFID sensor network [21]. Daliri et al. carried out research on wireless passive strain measurement applications using circular microstrip patch antenna (CMPA) sensors, proposed a CMPA operation at $1.5 \mathrm{GHz}$, and studied different materials for tag antennas [22]. Using high-quality dielectric materials as the tag antenna substrate can measure strain at a distance of $20 \mathrm{~cm}$ from the reader, while the strain at $5 \mathrm{~cm}$ can only be measured with RF4 dielectric materials [23].

For a defect sensing antenna, Shishir et al. designed a chipless passive structural health monitoring sensor based on a frequency selective surface array and a wireless microwave metamaterial sensor with a flexible substrate, whose electromagnetic characteristics are related to the antenna geometry; the antenna can detect the damage location [24]. Caizzone and Giampaolo studied and designed a pair of passive PIFA tag sensing antennas and placed two PIFA tags on each side of the defect, which can detect the width of the concrete structure defect [25]. Zhang and Tian proposed a specific three-dimensional antenna sensor for the detection and characterization of early metal corrosion; its size was $20 \mathrm{~mm} \times 20 \mathrm{~mm} \times 16 \mathrm{~mm}$, which inherits pulsed eddy current nondestructive testing advantages and provides a distributed monitoring cost-effective method [26]. MartinezCastro et al. detected longer defect changes by using the composite sensor array [27]. Marindra et al. proposed a chipless RFID sensor tag, which integrates 4 end-loaded dipole resonators as a 4-bit ID encoder and a circular microstrip patch antenna resonator, and its size was $60 \mathrm{~mm} \times 60 \mathrm{~mm} \times 2 \mathrm{~mm}$. Sub-millimeter-level defects can be detected through experiments on natural fatigue defects [28]. Subsequently, a sensor tag with a size of $35 \mathrm{~mm} \times 35 \mathrm{~mm}$ was raised. It was composed of cross-dipole patches and L-shaped patches with different lengths [29]. And then, they used the principal component analysis (PCA) method to detect metal surface cracks, corrosion, and other defects. Padmavathy and others studied microstrip patch antennas with the circular and rectangular slots. By using the 3D electromagnetic simulation software, the simulation results show that the antenna can detect the direction information of defects [30]. Xue et al. used the Rogers RT/duroid 5880 material as the substrate and dielectric board material to build a two-vertical capacitive microstrip line defect sensor antenna $45.4 \mathrm{~mm} \times 39 \mathrm{~mm} \times 0.5 \mathrm{~mm}$, which can detect defect widths within one hundredth of a millimeter, while affected by 


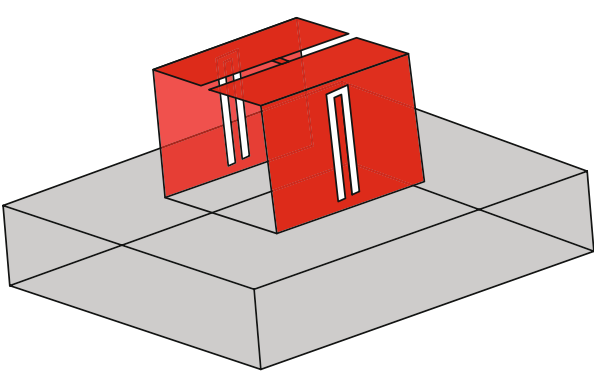

(a)

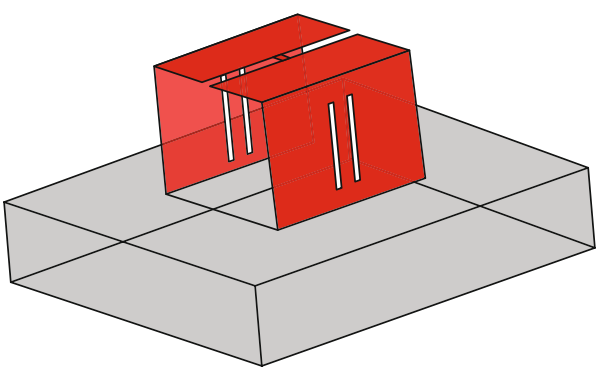

(c)

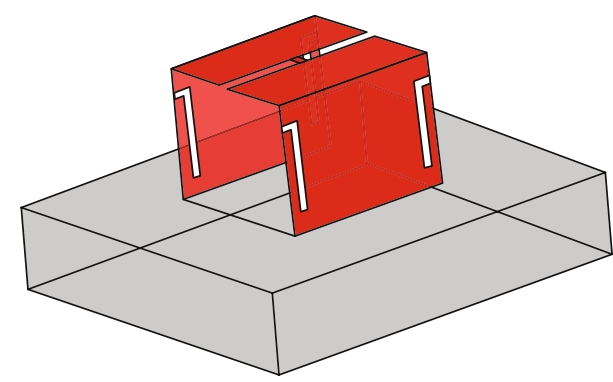

(b)

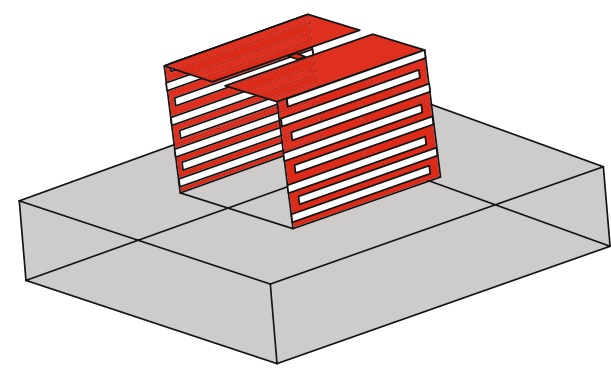

(d)

Figure 2: Bending dipole antenna with increased substrate thickness (slotted). (a) U-shaped slotted model. (b) L-shaped slotted model. (c) Hshaped slotted model. (d) Rectangular slotted model.

the environmental and manufacturing errors; the sensitivity coefficient obtained by the test is very different from the numerical simulation value [31].

The above research includes the use of special materials for tag antenna substrates and the use of array antennas to detect the metal or nonmetal defects. The important problem is that the above research can only detect the defect expansion in a single direction.

\section{Influence of the Metal Surface on a UHF RFID Dipole Tag Antenna}

3.1. Influence of the Metal Surface on Incident Electromagnetic Waves. From the perspective of energy collection, according to the principle of electromagnetic induction, when the antenna is close to the metal surface, the electromagnetic waves emitted by the reader will "distort" near the metal surface, resulting in a large tangential component and a small normal component [32]. Therefore, the antenna cannot obtain working energy by cutting a magnetic induction line to generate an induced current, which causes the passive antenna to fail to work normally. Meanwhile, parasitic capacitance will be generated inside the metal, causing electromagnetic friction, energy loss, and detuning of the antenna and reader; overall, system performance will decline [26].

From the perspective of communication capability, the antenna generates eddy current inside the whole. When the antenna is close to the metal surface, it will absorb the electromagnetic wave energy and convert it into its own electric field energy, which causes electromagnetic wave energy to decrease sharply. Finally, a part of the energy lost is in the form of heat [33]. An induced magnetic field will be produced by eddy current, and its lines will be perpendicular

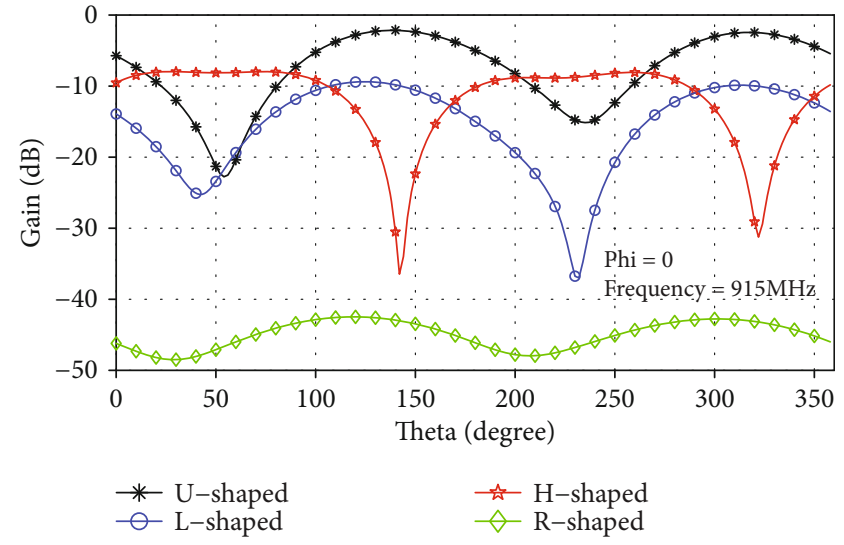

Figure 3: Two-dimensional gain graph with different slotting methods.

to the metal surface and opposite to the direction of electromagnetic waves, which will cause the magnetic field strength to be greatly attenuated near the metal surface [32], and the communication ability between the reader and the antenna will be hindered.

3.2. Influence of the Metal Surface on Performance Parameters of a Tag Antenna. Metal has a large impact on antenna impedance. Due to the radiation of metal boundary conditions, antenna reactance is reduced. Absorbing materials can be used to overcome this problem. A capacitance is also formed between the metal surface and the antenna, which will affect capacitive reactance of the antenna itself, and even worse, this influence cannot be eliminated. The field strength is close to zero near the metal surface, and the radiation efficiency of the antenna is seriously attenuated. Only 


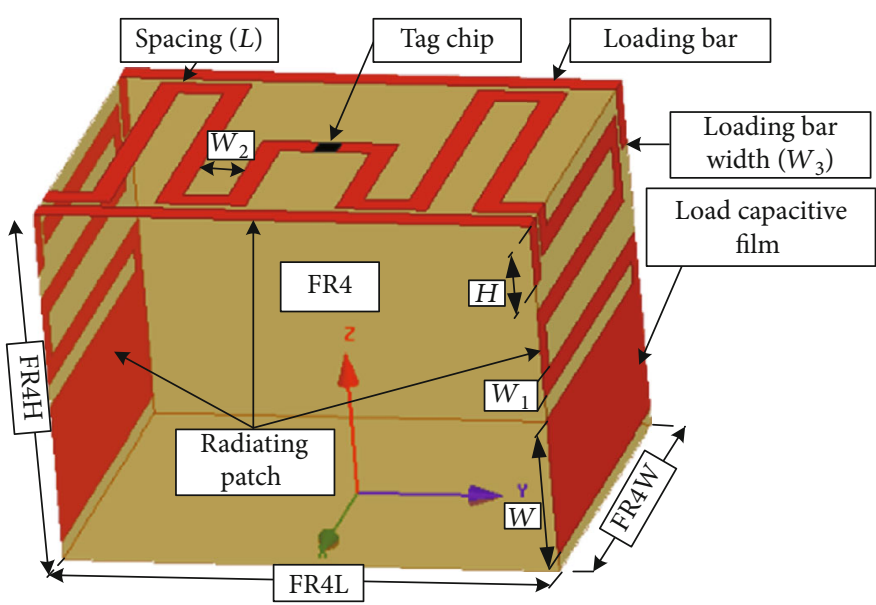

(a)

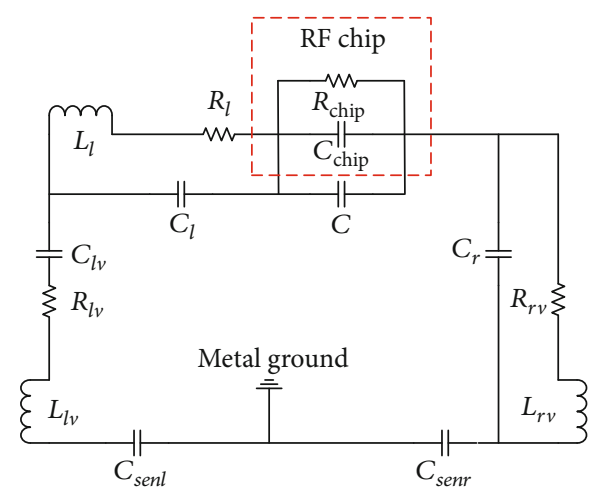

(b)

FIGURE 4: 3D patch bending dipole antenna model and equivalent circuit diagram. (a) 3D patch bending dipole antenna model. (b) Equivalent circuit diagram of the $3 \mathrm{D}$ patch bending dipole antenna.

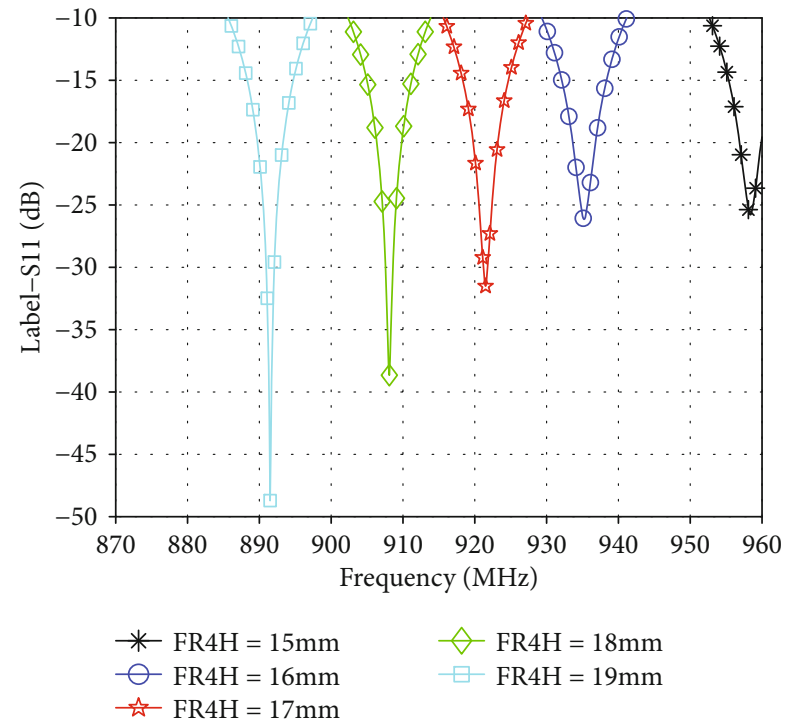

FIGURE 5: Simulation and verification of tag structure parameters.

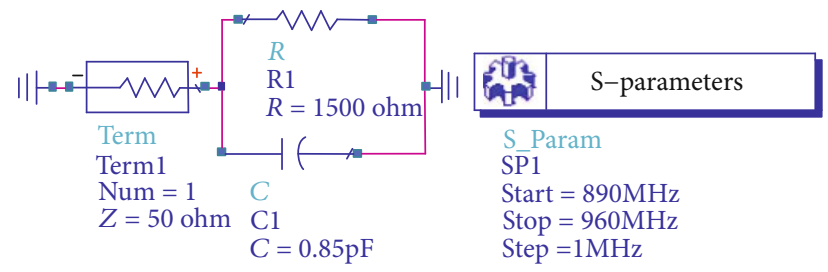

Figure 6: Chip equivalent circuit diagram.

when the antenna is $0.25 \lambda$ away from the metal surface [27] will it obtain the largest energy.

\section{Modeling and Analysis of a 3D Bent Patch Dipole Antenna}

In response to the problems discussed in Section 3, since the magnetic induction lines near the metal plane only have tan-

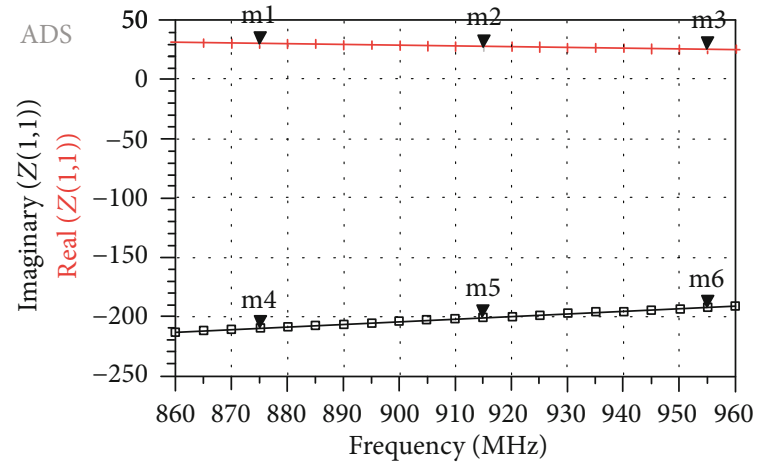

FIGURE 7: Impedance change of the chip at different operating frequencies.

TABLE 1: Chip impedance at three operating frequencies.

\begin{tabular}{lcc}
\hline $\mathrm{m} 1(875 \mathrm{MHz})$ & $\mathrm{m} 2(915 \mathrm{MHz})$ & $\mathrm{m} 3(955 \mathrm{MHz})$ \\
\hline$Z_{1}=29.9-j 209.7$ & $Z_{2}=27.4-j 200.9$ & $Z_{3}=25.2-j 192.8$ \\
\hline
\end{tabular}

gent vectors and the normal vector component is close to zero, the planar label antenna cuts the magnetic field lines to obtain low energy. Considering that antenna radiation efficiency is directly proportional to the electrical size of the antenna, the available space is used as much as possible [34]. Suppose that the label antenna is designed by increasing the thickness of the label dielectric substrate. The antenna can be properly away from the device metal surface under test, and it can be bent on the side of the substrate. By doing so, the magnetic field lines can be cut by the antenna arm on the side to obtain the driving energy, and also, the size of the tag can be reduced. According to the radiation principle of the rectangular microstrip patch antenna, it can be known that the path length of the excitation current is inversely proportional to the resonant frequency of the entire tag antenna by using two gaps at the two open ends for radiation. Consequently, the patch antenna uses a slot method to make the current on the antenna surface tortuously flow so as to 


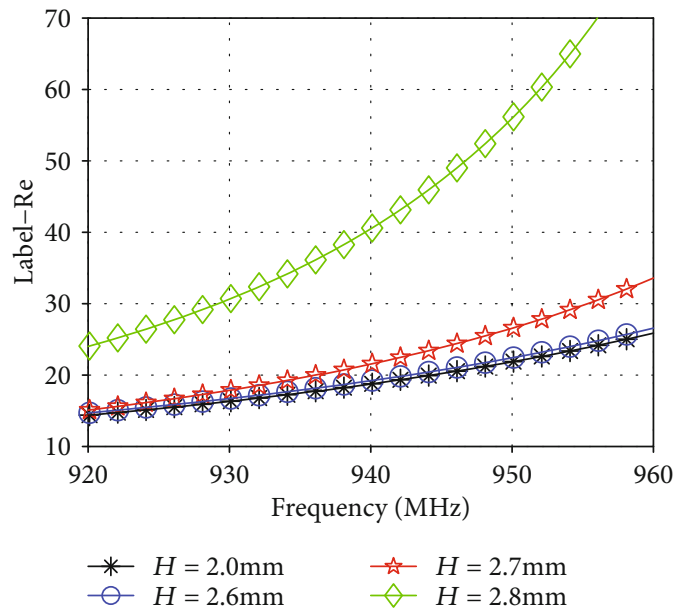

(a)

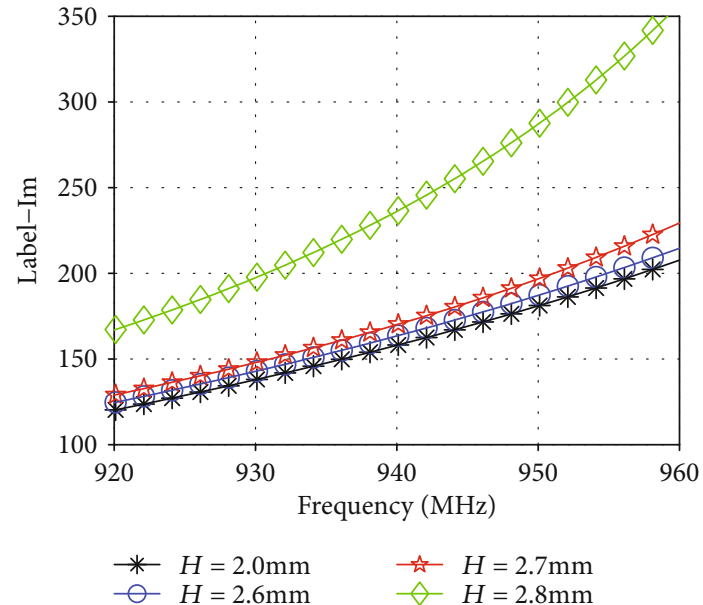

(b)

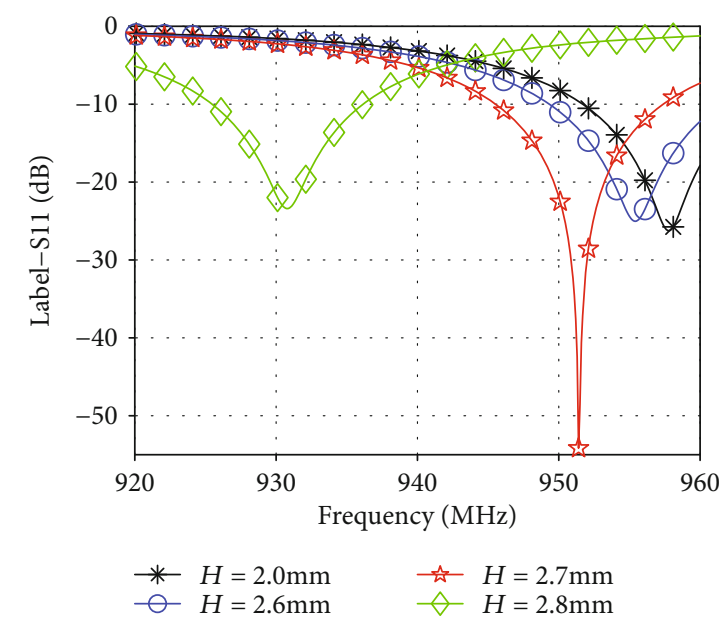

(c)

Figure 8: Effect of vertical depth $H$ of the loading horizontal strip on the antenna impedance and resonance frequency. (a) Antenna impedance real part. (b) Antenna impedance imaginary part. (c) Antenna resonance frequency.

increase the effective path of the current. At the same operating frequency, antenna size can be reduced to achieve miniaturization. There are many ways with slotting, such as $\mathrm{U}$-shaped groove, L-shaped groove, $\mathrm{H}$-shaped groove, and rectangular groove. The slotted current paths are shown in Figure 1.

As shown in Figure 2, while increasing the thickness of the tag antenna base, the end of the tag antenna is bent to the base side and different slotting techniques are used under the same model. The two-dimensional gain curves with different slotting methods are shown in Figure 3. Through rectangular slotting, the antenna gain is higher in most of the directions, and the omnidirectionality is better in the xoz plane (phi $=0)$.

The tag antenna is used for characterizing metal structure defects. The base material of this research object is the FR4 epoxy board with high heat resistance and moisture resistance. Its dielectric constant is 4.4 , and its loss tangent angle is 0.02 . In order to adjust antenna impedance to match tag chip impedance, horizontal bars are provided on both sides of the antenna, and capacitor pieces are provided at antenna ends, and then, the rectangular slot method is used to establish the antenna model. Finally, a three-dimensional model of a curved dipole tag antenna is proposed. The antenna structure model and parameters are shown in Figure 4(a). Figure 4(b) shows the equivalent circuit model of the tag model on the metal surface, where $C$ represents the capacitance formed at the near end of the feed, and $C_{\mathrm{l}}, R_{\mathrm{l}}$, and $L_{\mathrm{l}}$ represent the capacitance, resistance, and inductance of antenna structure on the upper left, respectively. $R_{\mathrm{lv}}$ and $L_{\mathrm{lv}}$ represent the resistance and inductance of the antenna structure on the left side of the tag. $C_{\mathrm{lv}}$ indicates the capacitance between the upper structures of the left antenna structure domain. The left side of the antenna is separated from the top and right sides only for impedance adjustment. $C_{\mathrm{r}}, R_{\mathrm{rv}}$, and $L_{\mathrm{rv}}$ indicate the capacitance, resistance, and inductance of the upper right and right structures of the tag, respectively. $C_{\text {senl }}$ and $C_{\text {senr }}$ indicate the capacitance formed between the metal ground and the tag. The changes in the metal ground will affect $C_{\text {senl }}$ and $C_{\text {senr }}$, which will affect antenna impedance changes, which indirectly cause the impedance mismatch between the antenna and the tag chip. Then, the 


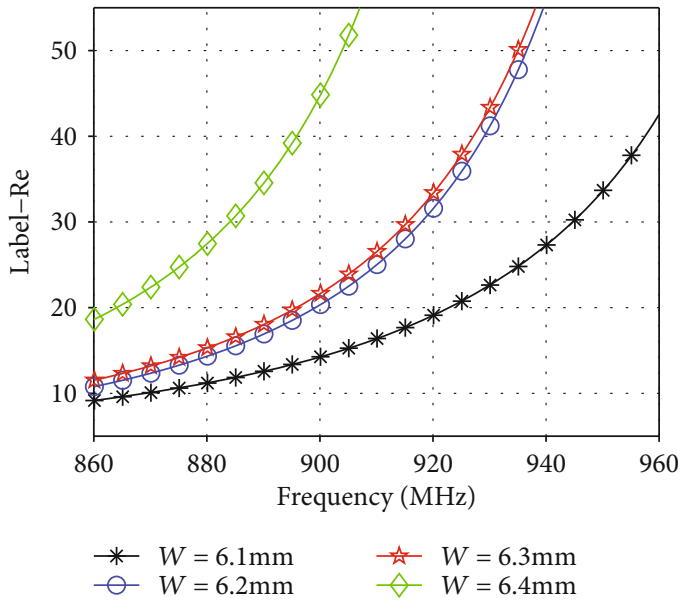

(a)

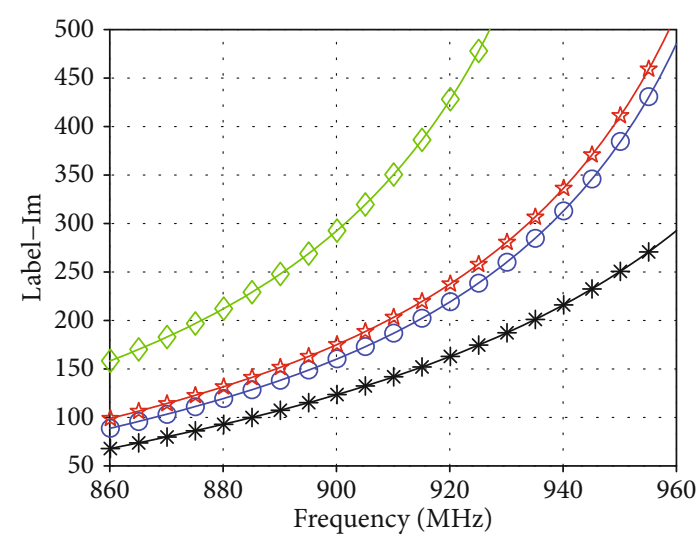

$\begin{array}{ll}* W=6.1 \mathrm{~mm} & \stackrel{\sim}{n} W=6.3 \mathrm{~mm} \\ \ominus W=6.2 \mathrm{~mm} & \triangleleft W=6.4 \mathrm{~mm}\end{array}$

(b)

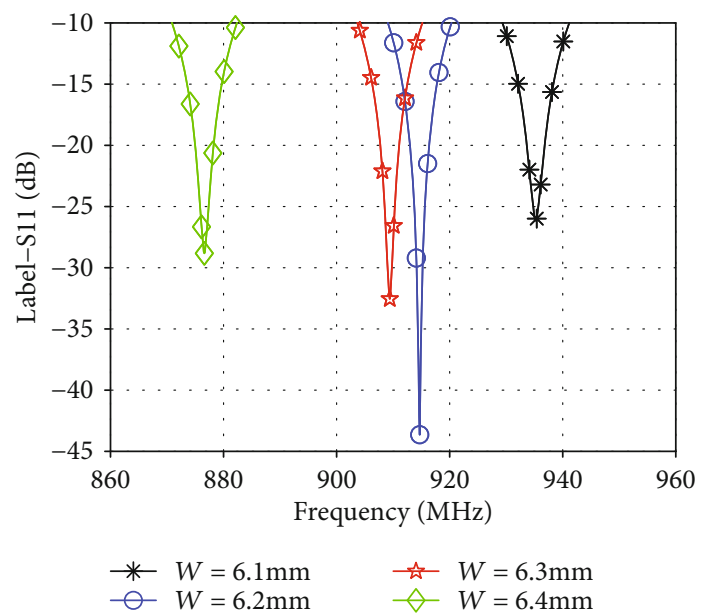

(c)

FIGURE 9: Effect of vertical depth $W$ of the capacitive piece at both ends of the antenna on the antenna impedance and resonance frequency. (a) Antenna impedance real part. (b) Antenna impedance imaginary part. (c) Antenna resonance frequency.

resonance frequency will change. This enables monitoring of metal defect expansion.

At present, readers in commercial ultra-high-frequency (UHF) RFID systems can recognize frequency bands from $860 \mathrm{MHz}$ to $960 \mathrm{MHz}$, and the antenna frequency is $915 \mathrm{MHz}$. Structural parameters need to be adjusted to optimize the impedance matching between the chip and the antenna when optimizing design, which will result in a decreased harmonic frequency. So, if the antenna resonance frequency is $930 \mathrm{MHz}$, the general rectangular microstrip antenna length $(l)$ and width $(w)$ are calculated as follows [35]:

$$
\begin{gathered}
l=\frac{c \times\left(\varepsilon_{f r 4 e}\right)^{-1 / 2}}{2 f}-2 \Delta l, \\
w=\left(\frac{2}{\varepsilon_{f r 4}+1}\right)^{1 / 2} \times \frac{c}{4 \times f} .
\end{gathered}
$$

The equivalent dielectric constant $\left(\varepsilon_{f r 4 e}\right)$ of the antenna dielectric substrate for the rectangular patch and the equivalent extension length $(\Delta l)$ caused by the fringe field of the microstrip antenna are as follows:

$$
\begin{aligned}
\varepsilon_{f r 4 e} & =\frac{\varepsilon_{f r 4}+1}{2}+\frac{\varepsilon_{f r 4}-1}{2} \times\left(\frac{w}{w+12 h}\right)^{1 / 2}, \\
\Delta l & =0.412 \times \frac{\left(\varepsilon_{f r 4 e}+0.3\right) \times((w / h)+0.264)}{\left(\varepsilon_{f r 4 e}-0.258\right) \times((w / h)+0.8)} \times h .
\end{aligned}
$$

The dielectric thickness $h$ of the preset tag antenna is $16 \mathrm{~mm}$; then, the calculated $l$ is $72 \mathrm{~mm}$ and $w$ is $48 \mathrm{~mm}$. In this paper, the two ends of the tag antenna are folded on both sides to reduce the size. Therefore, the equivalent antenna width should be set to $16 \mathrm{~mm}$, which is one-third of $w$. The opposite antenna ends can increase antenna capacitive reactance and impedance. It is beneficial for getting energy when the antenna arms cut the tangential 


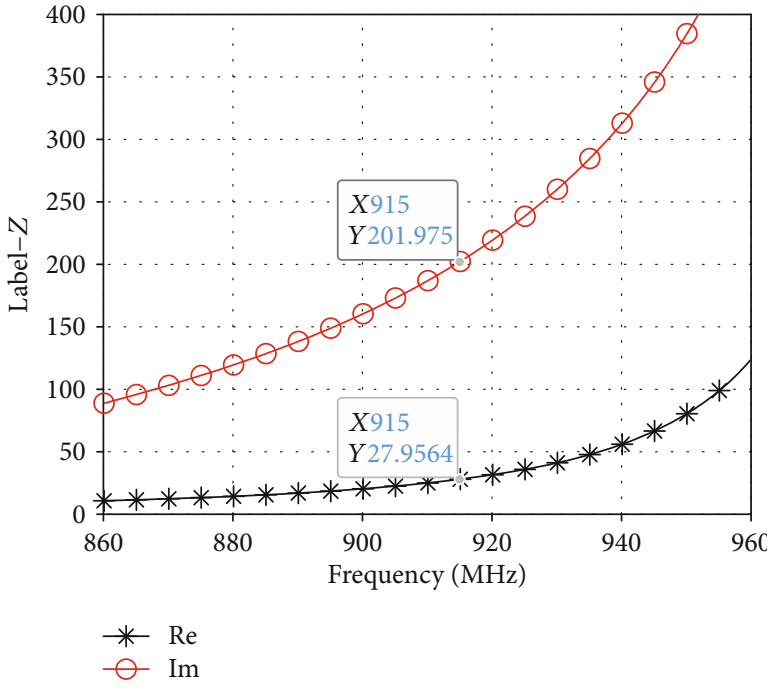

(a)

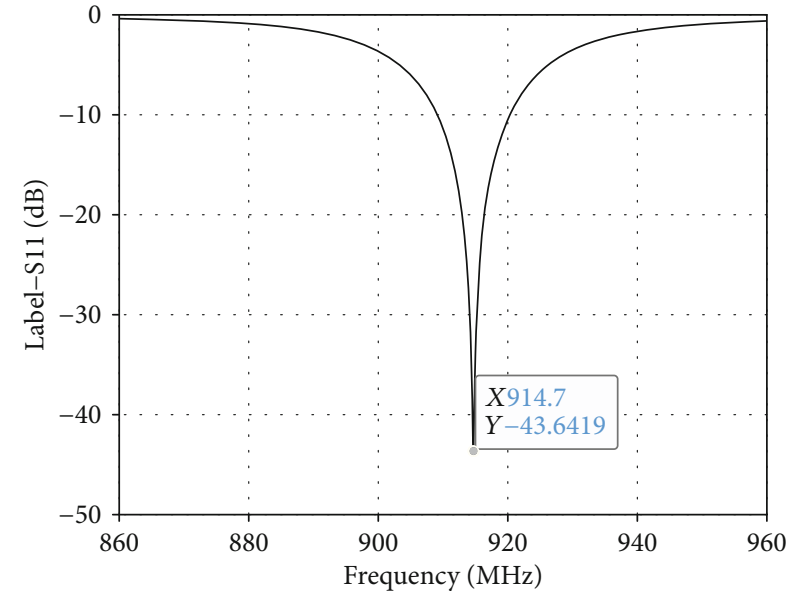

(b)

FIGURE 10: Antenna impedance and resonance frequency after parameter optimization. (a) Antenna impedance. (b) Antenna resonance frequency (return loss).

TABle 2: Antenna structure parameter size (unit: mm).

\begin{tabular}{lccccccccc}
\hline Parameter & FR4L & FR4W & FR4H & $W$ & $W_{1}$ & $W_{2}$ & $W_{3}$ & $L$ & $H$ \\
\hline Size & 22 & 16 & 16 & 6.2 & 1 & 2 & 1 & 0.5 & 2.8 \\
\hline
\end{tabular}

magnetic field lines. The base height (FR4H) of the antenna is set to $16 \mathrm{~mm}$, the width (FR4W) is set to $16 \mathrm{~mm}$, and the length (FR4L) is set to $22 \mathrm{~mm}$. The parameters are determined by simulation, as shown in Figure 5; when the $\mathrm{FR} 4 \mathrm{H}$ is $16 \mathrm{~mm}$, the antenna resonant frequency is slightly greater than $930 \mathrm{MHz}$, so parameters are set reasonably.

\section{Design of a 3D Bent Patch Dipole Antenna}

The RFID sensor tag is composed of a chip and an antenna. Passive RFID sensor tag impedance matching is particularly important. Impedance matching can reduce the scattering effects caused by echoes formed inside the tag. The energy utilization rate is high, which can increase the sensor tag antenna and the reader distance. According to the Alien Higgs-3 passive RF chip data sheet, ADS software is used to establish a chip equivalent circuit simulation diagram, as shown in Figure 6.

Simulation results show that Alien Higgs-3 chip impedance changes with the operating frequency as shown in Figure 7. As the operating frequency increases, the equivalent reactance of the radio frequency chip decreases and the capacitive reactance increases. The impedances are shown in Table 1 at $875 \mathrm{MHz}, 915 \mathrm{MHz}$, and $955 \mathrm{MHz}$ operating frequencies for reference.

If the antenna operating frequency considers the midfrequency $915 \mathrm{MHz}$ between $860 \mathrm{MHz}$ and $960 \mathrm{MHz}$, the antenna impedance should be designed as $Z_{2}^{*}=27.4+j$ 200.9 .

The basic antenna model and impedance have been determined. When the working frequency is $915 \mathrm{MHz}$, the distance between the antenna surface and the radiation boundary should be greater than $0.25 \lambda$; then, the ideal boundary condition is set to $180 \mathrm{~mm} \times 180 \mathrm{~mm} \times 118 \mathrm{~mm}$. The antenna is mainly used to characterize metal defects. So an aluminum block with a size of $130 \mathrm{~mm} \times 50 \mathrm{~mm} \times 20$ $\mathrm{mm}$ is placed under the antenna. Through Ansys highfrequency structure simulator (HFSS) 15.0 modeling and antenna parameter tuning, its structural parameters are shown in Figure 4. Figures 8 and 9 show that the simulation results of the vertical depth $(H)$ of the antenna loading horizontal strip and the vertical depth $(W)$ of the capacitive piece at both antenna ends vary, respectively. The frequency moves to a low frequency, and the vertical depth of the capacitive plate has a great influence on the resonance frequency.

As shown in Figure 10, when $H=2.8 \mathrm{~mm}$ and $W=6.2$ $\mathrm{mm}$, the tag antenna impedance is $Z_{2}^{\prime}=27.9564+j 201.975$ and its return loss is as low as $-43.6419 \mathrm{~dB}$, which achieves good conjugate matching with the tag chip. The structural parameters of the optimized antenna are shown in Table 2.

Figure 11 shows the 2D directional gain pattern and 3D radiation pattern of the tag antenna on the metal surface. The label has better omnidirectionality in the space area above the metal plate, and the radiation area is wide. The RFID reader in a large space can recognize the tag.

\section{Analysis of Metal Defect Extended Induction Capability}

This paper mainly studies that antenna performance parameters change, which are caused by defects on the surface of metal structures. Defect depth is an important indicator for judging the carrying capacity of metal. The deeper the defect, the lower the metal's compression resistance and the higher the risk factor. The defect width can simulate the expansion trend of the defect on the metal surface, and then, we can 

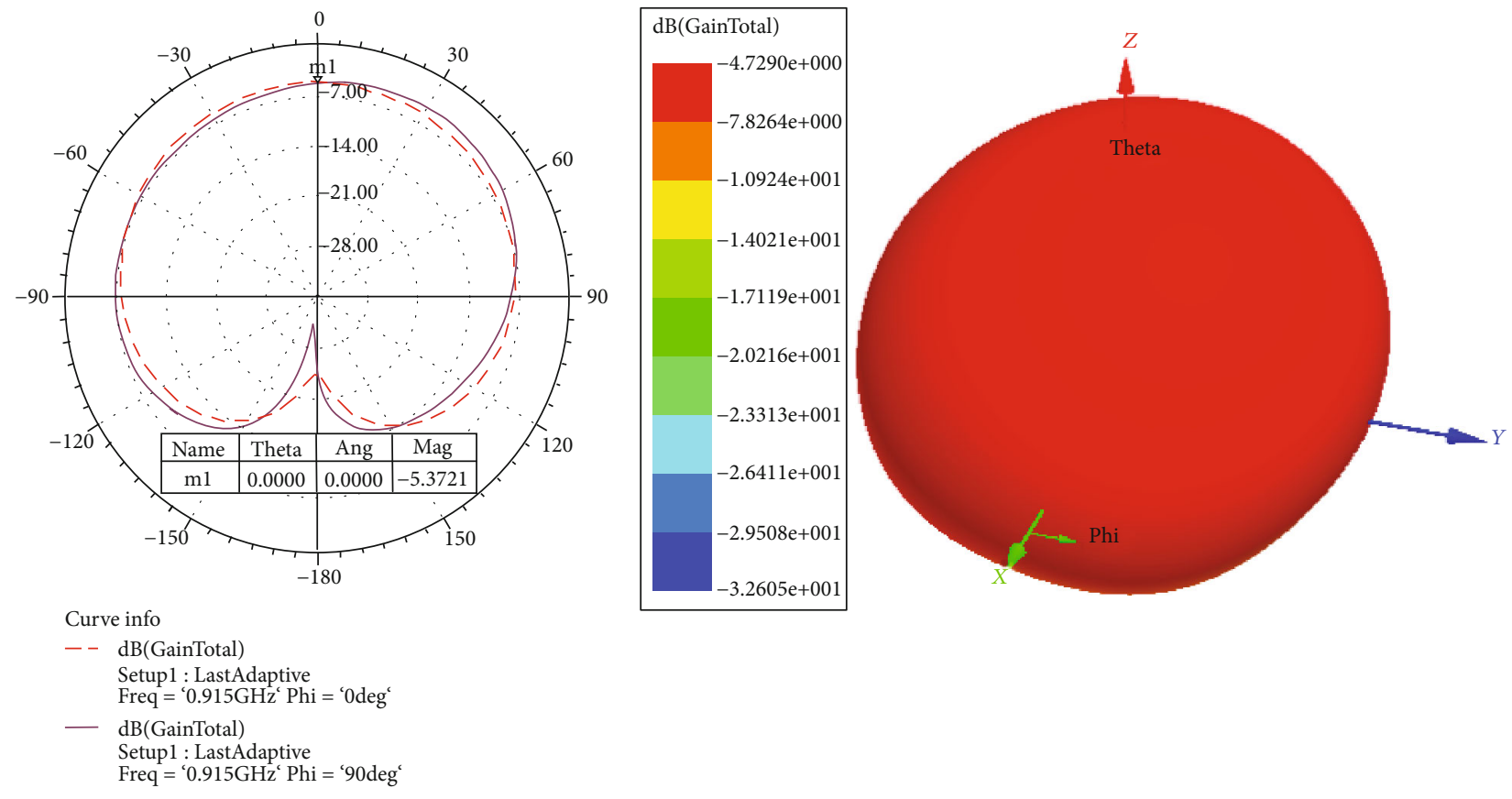

(a)

(b)

FIGURE 11: Full pattern of antenna directivity gain and radiation. (a) Antenna 2D directional gain diagram. (b) Antenna 3D radiation diagram.

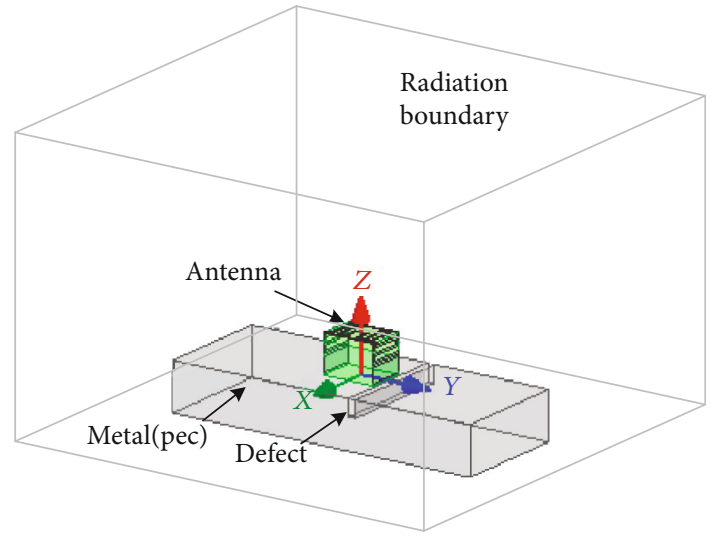

Figure 12: Simulation of surface defects on metal structures.

study the relative position of the defect and label to locate the position where the defect occurs on the surface of metal structures.

6.1. Analysis of the Defect Depth of Metal Structure Surfaces. A smooth defect is simulated on the metal structure surface, as shown in Figure 12. When the defect is $12 \mathrm{~mm}$ to the right of the antenna and its width is $3 \mathrm{~mm}$, its depth changes. The results show that when the metal surface depth deepens, the real and imaginary parts of antenna impedance decrease (same frequency), the antenna resonance frequency moves toward a high frequency, and the return loss coefficient increases, as shown in Figure 13.
In the field of antenna design, the radiation pattern indicates the radio wave strength in different directions of the antenna. Figure 14 shows the two-dimensional gain of the antenna at various defect depths. The simulation result shows that as the metal surface structural defect depth expands, it has little effect on the radiation effect of the tag antenna and the directional gain, which indicates that under normal operating conditions, defect depth expansion within a certain range will not cause the reader to fail to recognize the label.

6.2. Analysis of the Surface Defect Width of Metal Structures. The defect position is $12 \mathrm{~mm}$ away from the antenna center, and its depth is $5 \mathrm{~mm}$; then, its width expands to the right. The antenna impedance and resonance frequency with width change are shown in Figure 15. The results show that as the surface defect width of the metal structure expands, the real and imaginary parts of antenna impedance decrease (same frequency), and its resonance frequency moves to a high frequency.

Similarly, Figure 16 shows the two-dimensional gain of the tag antenna at various defect widths. As the defect width generated on the metal surface structure changes, the radiation surface and gain of the tag antenna change less.

6.3. Analysis of the Relative Distance between the Surface Defects of Metal Structures and the Antenna. The defect width and depth are set to $1 \mathrm{~mm}$. The relative distance between the surface defect of the simulated metal structure and the antenna center is changed, and the defect depth and width remain unchanged. Antenna impedance and resonance frequency results are shown in Figure 17. As the 

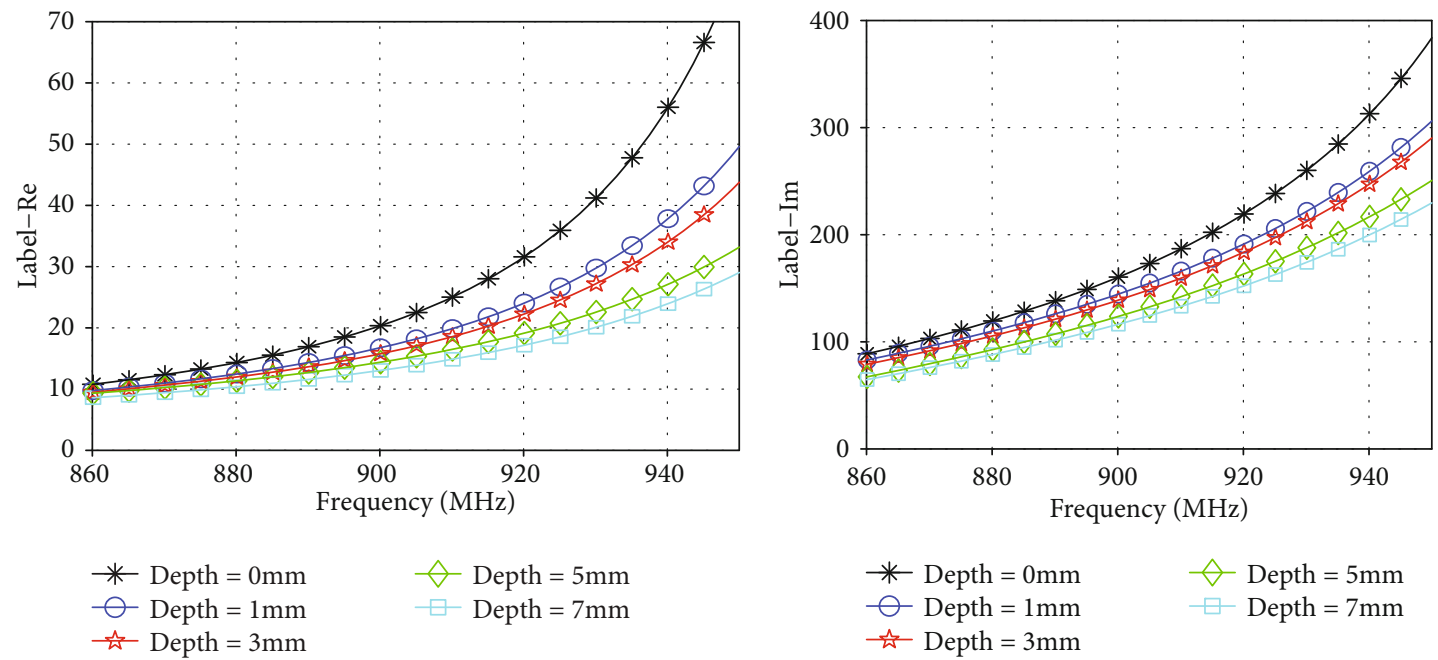

(a)

(b)

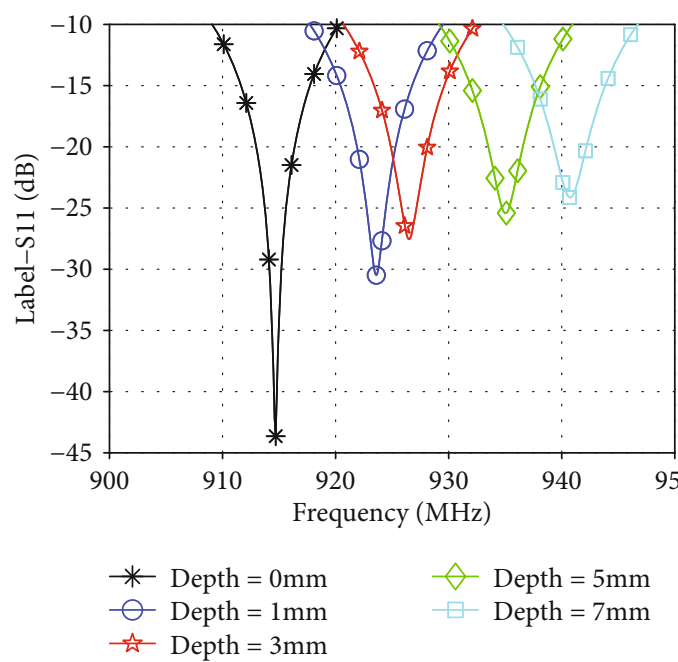

(c)

FIGURE 13: Simulation results of antenna performance parameters changing with increasing defect depth. (a) Real part of the antenna. (b) Imaginary part of the antenna. (c) Antenna resonance frequency.

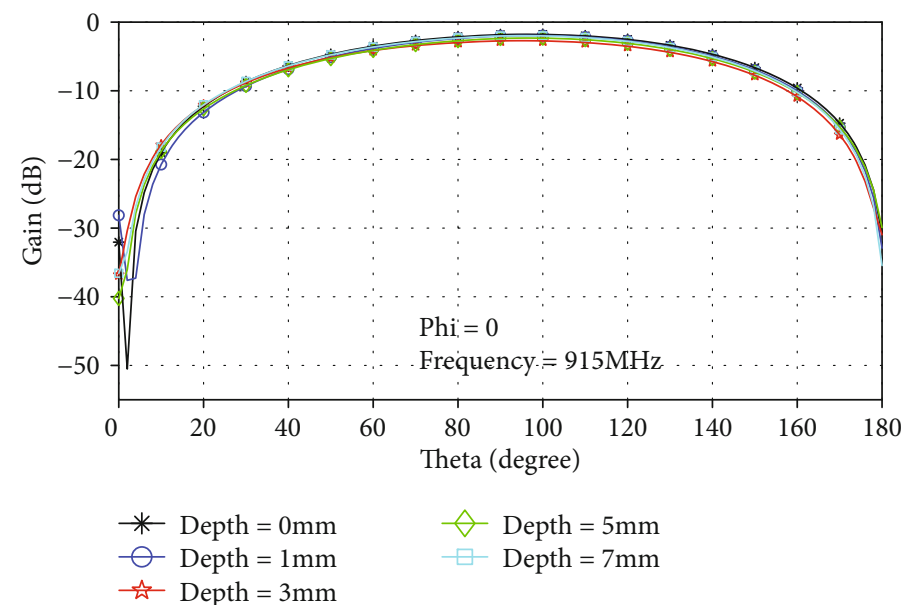

FIGURE 14: The two-dimensional gain of the tag antenna at various defect depths. 

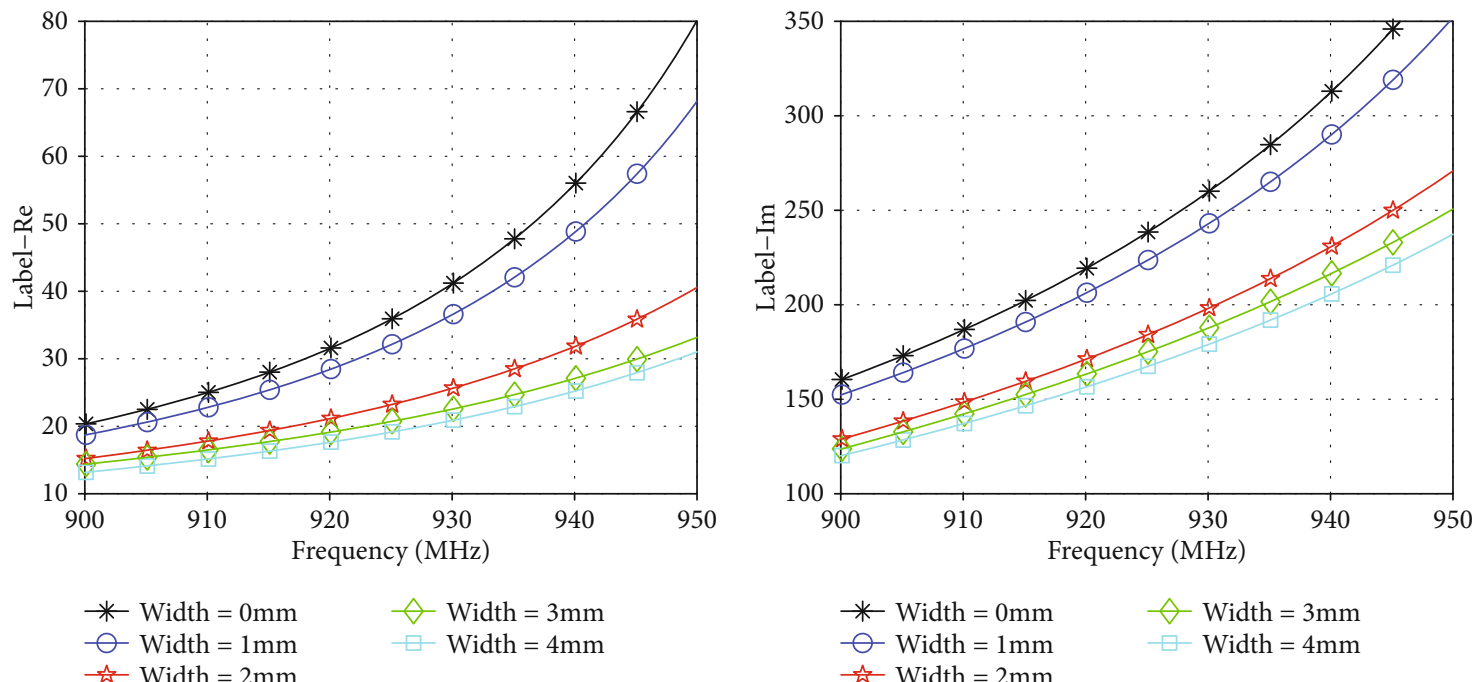

(a)

(b)

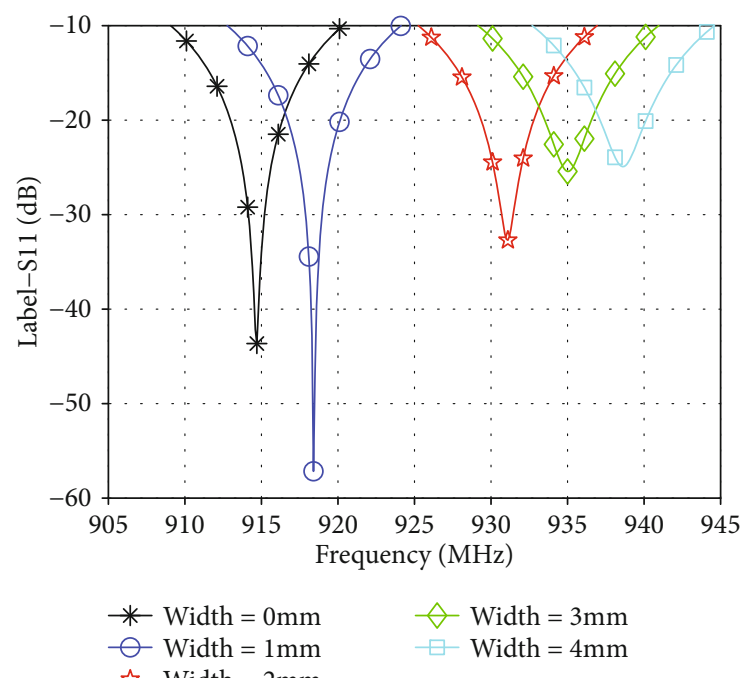

(c)

FIGURE 15: Simulation results of antenna performance parameters as defect width increases. (a) Real part of the antenna. (b) Imaginary part of the antenna. (c) Antenna resonance frequency.

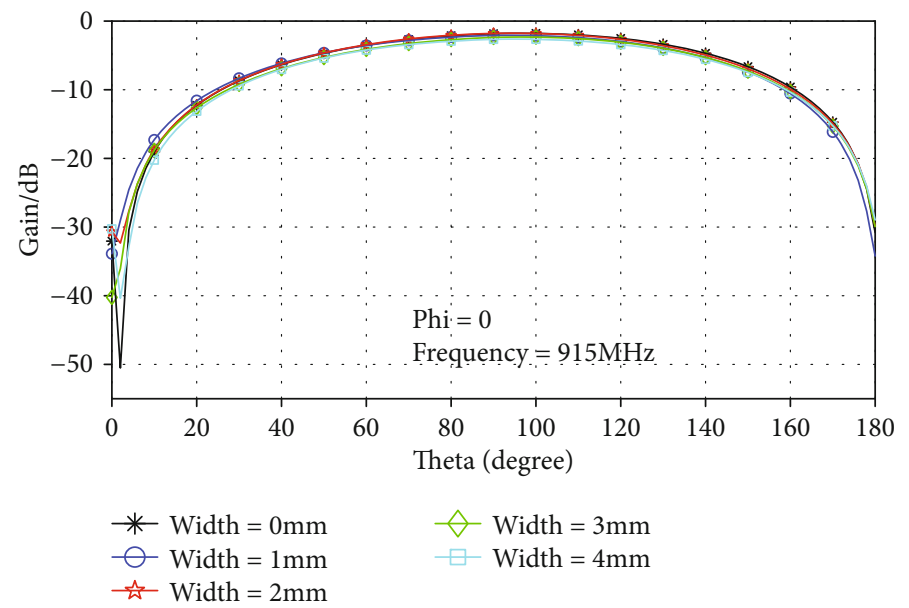

Figure 16: The two-dimensional gain of the tag antenna at various defect widths. 


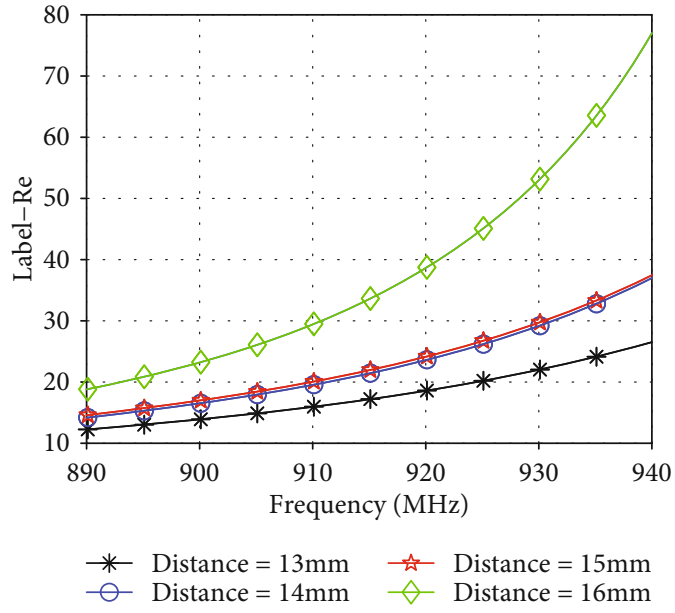

(a)

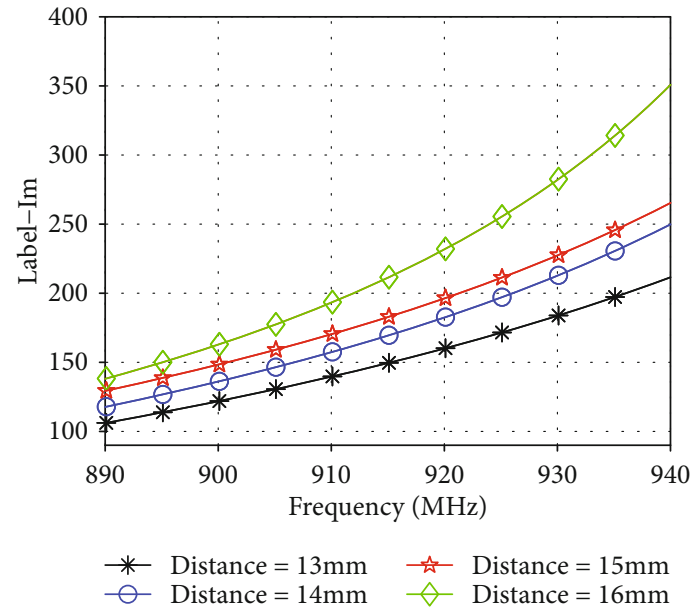

(b)

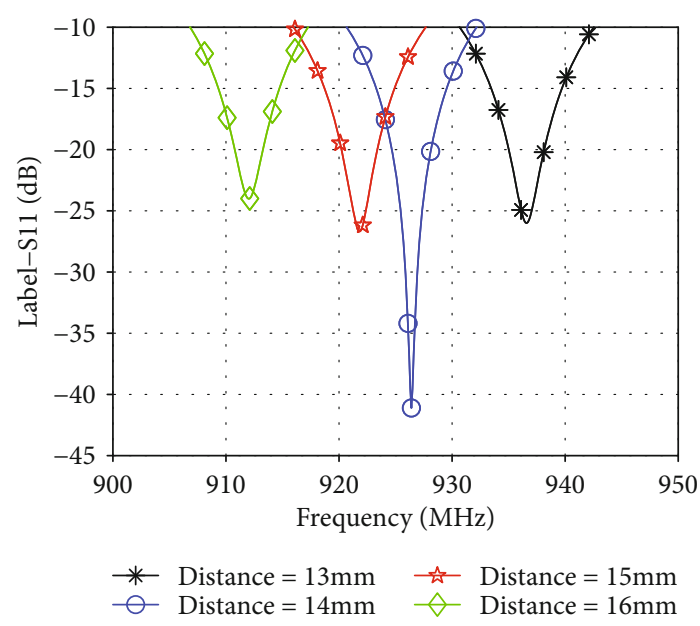

(c)

FIgURE 17: Simulation results of antenna performance parameters as a function of the relative distance between the defect and the tag antenna. (a) Real part of the antenna. (b) Imaginary part of the antenna. (c) Antenna resonance frequency.

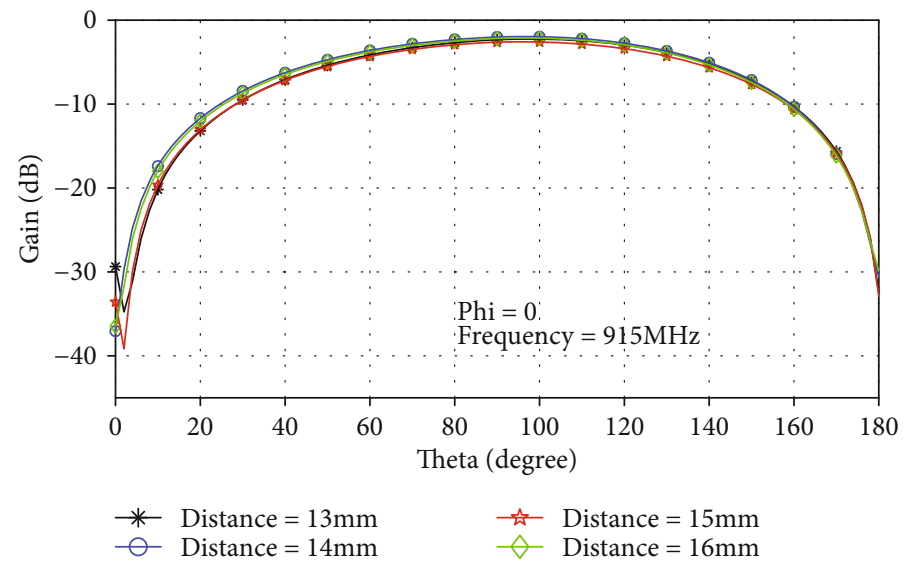

Figure 18: The two-dimensional gain diagram of the tag antenna when the relative distance between the defect and the tag antenna is different. 
relative distance between the metal structure defect and the sensing antenna increases, the real and imaginary antenna impedance values show an increasing trend (same frequency), and its resonance frequency moves to a low frequency, which is different from the results of defect depth and width changes.

The two-dimensional polar coordinate gain of the antenna at different distances is shown in Figure 18. When the precision is $1 \mathrm{~mm}$, the antenna gain changes little with the position of the defect on the metal structure surface. The gain in all directions will not be greatly affected by the distance change.

\section{Conclusion}

The purpose of this paper was to study the multi-directional expansion of metal defects by antennas. A 3D patch-bend dipole antenna with an operating frequency of $915 \mathrm{MHz}$ was simulated using FR-4 epoxy substrate and analyzed by Ansys HFSS 15.0. The simulation results show that the antenna can detect the depth ( $2 \mathrm{~mm}$ accuracy) and width ( $1 \mathrm{~mm}$ accuracy) of smooth defects ( $1 \mathrm{~mm}$ accuracy) on the metal structure surface and the locations of smooth defects on the metal surface, which is relative to the sensor tag antenna. Neither the radiation direction nor the radiation direction gain has a large effect. Although this antenna is only suitable for the detection of surface smooth defects on metal structures on the right side of the antenna, this article provides a new design reference model for tag antennas. At the same time, the 3D antenna simulation model can characterize the specific smooth defect multiple expansion directions by a single antenna. This tag antenna has huge potential in nondestructive testing and SHM.

\section{Data Availability}

No specific dataset is required.

\section{Conflicts of Interest}

The authors declare that there are no conflicts of interest regarding the publication of this paper.

\section{Acknowledgments}

This work is supported by Sichuan Science and Technology Program (No. 2019JDTD0019).

\section{References}

[1] K. M. Abbas, G. Manogaran, C. Thota, D. Lopez, V. Vijayakumar, and R. Sundarsekar, Studies in big data series: internet of things and big data technologies for next generation healthcare, Springer International Publishing, 2017.

[2] A. Gryguć, S. B. Behravesh, S. K. Shaha et al., "Multiaxial cyclic behaviour of extruded and forged AZ80 Mg alloy," International Journal of Fatigue, vol. 127, pp. 324-337, 2019.
[3] Y. Yao, S. T. E. Tung, and B. Glisic, "Crack detection and characterization techniques-an overview," Structural Control \& Health Monitoring, vol. 21, no. 12, pp. 1387-1413, 2014.

[4] U. D. Gandhi, P. M. Kumar, R. Varatharajan, G. Manogaran, R. Sundarasekar, and S. Kadu, "Hiotpot: surveillance on IoT devices against recent threats," Wireless Personal Communications, vol. 103, no. 2, pp. 1179-1194, 2018.

[5] M. Pathak, S. Alahakoon, M. Spiryagin, and C. Cole, "Rail foot flaw detection based on a laser induced ultrasonic guided wave method," Measurement, vol. 148, article 106922, 2019.

[6] S. Ahmed, C. Reboud, P. E. Lhuillier, P. Calmon, and R. Miorelli, "An adaptive sampling strategy for quasi real time crack characterization on eddy current testing signals," NDT \& Einternational, vol. 103, pp. 154-165, 2019.

[7] J. Li, T. Yu, M. Zhang, J. Zhang, L. Qiao, and T. Wang, “Temperature and crack measurement using distributed optic-fiber sensor based on raman loop configuration and fiber loss," IEEE Photonics Journal, vol. 11, no. 4, article 6802113, pp. 113, 2019.

[8] G. Manogaran, D. Lopez, C. Thota, K. M. Abbas, S. Pyne, and R. Sundarasekar, "Big data analytics in healthcare internet of things," in Innovative Healthcare Systems for the 21st Century. Understanding Complex Systems, H. Qudrat-Ullah and P. Tsasis, Eds., Springer, Cham, 2017.

[9] J. P. Lynch and K. J. Loh, "A summary review of wireless sensors and sensor networks for structural health monitoring," The Shock and Vibration Digest, vol. 38, no. 2, pp. 91-128, 2006.

[10] Y. L. Guo, Q. P. Wang, H. Huang, W. Tan, and G. X. Zhang, "The research and design of routing protocols of a wireless sensor network in the coal mine data acquisition," in 2007 International Conference on Information Acquisition, pp. 2528, Seogwipo-si, South Korea, July 2007.

[11] S. J. Ashaj and E. Erçelebi, "Energy saving data aggregation algorithms in building automation for health and security monitoring and privacy in medical internet of things," Journal of Medical Imaging and Health Informatics, vol. 10, no. 1, pp. 204-210, 2020.

[12] R. Bhattacharyya, C. Floerkemeier, and S. Sarma, "Low-cost, ubiquitous RFID-tag-antenna-based sensing," Proceedings of the IEEE, vol. 98, no. 9, pp. 1593-1600, 2010.

[13] M. M. Tentzeris, A. Georgiadis, and L. Roselli, "Energy harvesting and scavenging scanning the issue," Proceedings of the IEEE, vol. 102, no. 11, pp. 1644-1648, 2014.

[14] M. Mayer and N. Goertz, "RFID tag acquisition via compressed sensing: fixed vs. random signature assignment," IEEE Transactions on Wireless Communications, vol. 15, no. 3, pp. 2118-2129, 2016.

[15] R. Lodato and G. Marrocco, "Close integration of a UHFRFID transponder into a limb prosthesis for tracking and sensing," IEEE Sensors Journal, vol. 16, no. 6, pp. 18061813,2016

[16] F. Costa, A. Gentile, S. Genovesi et al., "A depolarizing chipless RF label for dielectric permittivity sensing," IEEE Microwave and Wireless Components Letters, vol. 28, no. 5, pp. 371-373, 2018.

[17] D. Alonso, Q. Y. Zhang, Y. Gao, and D. Valderas, "UHF passive RFID-based sensor-less system to detect humidity for irrigation monitoring," Microwave and Optical Technology Letters, vol. 59, no. 7, pp. 1709-1715, 2017.

[18] J. S. Lee, J. Oh, J. Jun, and J. Jang, "Wireless hydrogen smart sensor based on Pt/graphene-immobilized radio-frequency 
identification tag," ACS Nano, vol. 9, no. 8, pp. 7783-7790, 2015.

[19] X. Lai, Z. Cai, Z. Xie, and H. Zhu, "A novel displacement and tilt detection method using passive UHF RFID technology," Sensors, vol. 18, no. 5, article 1644, 2018.

[20] H. Huang, P. Y. Chen, C. H. Hung, R. Gharpurey, and D. Akinwande, "A zero power harmonic transponder sensor for ubiquitous wireless $\mu \mathrm{L}$ liquid- volume monitoring," Scientific Reports, vol. 6, no. 1, 2016.

[21] T. Kobayashi, T. Yamashita, N. Makimoto, S. Takamatsu, and T. Itoh, "Ultra-thin piezoelectric strain sensor 5 x 5 array integrated on flexible printed circuit for structural health monitoring by 2D dynamic strain sensing," in 2016 IEEE 29th International Conference on Micro Electro Mechanical Systems (MEMS), pp. 1030-1033, Shanghai, China, January 2016.

[22] A. Daliri, A. Galehdar, S. John, C. H. Wang, W. S. T. Rowe, and K. Ghorbani, "Wireless strain measurement using circular microstrip patch antennas," Sensors and Actuators, vol. 184, pp. 86-92, 2012.

[23] A. Daliri, A. Galehdar, W. S. T. Rowe, S. John, and C. H. Wang, "Quality factor effect on the wireless range of microstrip patch antenna strain sensors," Sensors, vol. 14, no. 1, pp. 595-605, 2014.

[24] I. R. Shishir, S. Mun, H. C. Kim, J. W. Kim, and J. Kim, "Frequency-selective surface-based chipless passive RFID sensor for detecting damage location," Structural Control and Health Monitoring, vol. 24, no. 12, article e2511, 2017.

[25] S. Caizzone and E. DiGiampaolo, "Wireless passive RFID crack width sensor for structural health monitoring," IEEE Sensors Journal, vol. 15, no. 12, pp. 6767-6774, 2015.

[26] J. Zhang and G. Y. Tian, "UHF RFID tag antenna-based sensing for corrosion detection \& characterization using principal component analysis," IEEE Transactions on Antennas and Propagation, vol. 64, no. 10, pp. 4405-4414, 2016.

[27] R. Martínez-Castro, S. Jang, J. Nicholas, and R. Bansal, “Experimental assessment of an RFID-based crack sensor for steel structures," Smart Material and Structures, vol. 26, no. 8, article $085035,2017$.

[28] A. M. J. Marindra and G. Y. Tian, "Chipless RFID sensor tag for metal crack detection and characterization," IEEE Transactions on Microwave Theory and Techniques, vol. 66, no. 5, pp. 2452-2462, 2018.

[29] A. M. J. Marindra and G. Y. Tian, "Multiresonance chipless RFID sensor tag for metal defect characterization using principal component analysis," IEEE Sensors Journal, vol. 19, no. 18, pp. 8037-8046, 2019.

[30] T. V. Padmavathy, D. S. Bhargava, P. Venkatesh, and N. Sivakumar, "Design and development of microstrip patch antenna with circular and rectangular slot for structural health monitoring," Personal and Ubiquitous Computing, vol. 22, no. 5-6, pp. 883-893, 2018.

[31] S. Xue, K. Xu, L. Xie, and G. Wan, "Crack sensor based on patch antenna fed by capacitive microstrip lines," Smart Materials and Structures, vol. 28, no. 8, article 085012, 2019.

[32] O. Rees-Lloyd, P. Charlton, S. Mosey, and R. Lewis, "Effects of relative motion on a Rayleigh wave electromagnetic acoustic transducer operating on aluminium," Insight, vol. 61, no. 2, pp. 83-89, 2019.

[33] Y. J. He and Z. Z. Pan, "Design of UHF RFID broadband antimetal tag antenna applied on surface of metallic objects," in
2013 IEEE Wireless Communications and Networking Conference (WCNC), pp. 4352-4357, Shanghai, China, April 2013.

[34] T. Bjorninen, A. Z. Elsherbeni, and L. Ukkonen, "Low-profile conformal UHF RFID tag antenna for integration with water bottles," IEEE Antennas and Wireless Propagation Letters, vol. 10, pp. 1147-1150, 2011.

[35] T. D. Amalraj and R. Savarimuthu, "Design and analysis of microstrip patch antenna using periodic EBG structure for cband applications," Wireless Personal Communications, vol. 109, no. 3, pp. 2077-2094, 2019. 